\title{
Numerical assessment of increasing photovoltaic self-sufficiency of a low energy residential building in Belgium by using heat pump and energy storage
}

\author{
Katarina Simic ${ }^{a, b}$, Klaas Thiers ${ }^{a}$, Hugo Monteyne ${ }^{a, b}$, Jan Desmet ${ }^{c}$ and \\ Michel De Paepe ${ }^{a, b}$ \\ a Department of Electromechanical, Systems and Metal Engineering, Sustainable Thermo-Fluid \\ Energy Systems research team, Ghent University, Ghent, Belgium, \\ Michel.DePaepe@UGent.be \\ b Flanders Make@UGent corelab EEDT MP, Flanders Make, Leuven, Belgium, \\ Michel.DePaepe@UGent.be \\ c Department of Electromechanical, Systems and Metal Engineering, EELAB/Lemcko, Ghent \\ University, Kortrijk, Belgium, JanJ.Desmet@UGent.be
}

\begin{abstract}
:
In the line of measures aiming to reduce the greenhouse emissions and the total energy use of residential buildings, all new buildings built from the year 2020 within the European Union must meet the requirements of so-called Nearly Zero Energy Buildings (NZEB). An NZEB represents a building with high energy performance and significant coverage of its energy demand by utilizing renewable energy sources through on-site energy generation. A self-sustained building represents a building, which is only using energy generated on site to meet its energy requirements. In this article, self-consumption and self-sufficiency of an NZEB are assessed through numerical, transient detailed models made in programming language Modelica and simulated in the software tool Dymola. The two-floor residential building is modelled as a dwelling with the space heating energy demand of $30 \mathrm{kWh} / \mathrm{m}^{2}$ year. The energy use of the building coincides with the occupancy profile of a family with four members with the dominating domestic hot water use over the space heating need. The space heating comfort conditions are attained with the low-temperature underfloor heating system. The domestic hot water demand is provided through a 300 I water tank. Both systems are coupled to an air to water heat pump. The aim of the research is to investigate the potential of increasing the self-consumption and self-sufficiency values by using thermal load shifting and electrical energy storage in order to compensate for the direct unbalance in optimal energy generation and energy use. For aspirations in achieving a complete self-sustainable dwelling, different sizes of energy storage and photovoltaic panels are used for the analysed case study conditions. However, special attention is paid to the available south roof space of the dwelling. For the use of $28 \mathrm{~m}^{2}$ of optimally positioned photovoltaic panels, the studied building achieves $49.1 \%$ of self-consumption and $27.2 \%$ self-sufficiency without any use of energy storages. With the electrical battery of $20 \mathrm{kWh}$ and thermal energy storage of $1000 \mathrm{I}$, the building can meet self-consumption of $89.8 \%$ and self-sufficiency of $49.8 \%$ for specific boundary conditions.
\end{abstract}

Keywords:

Heat pump; Energy storage; Renewable energy; Energy use; Residential building;

\section{Introduction}

According to the European Environment Agency (EEA), in 2017, the total emission of greenhouse gases in the European Union (EU) was 4,323 Mt of $\mathrm{CO}$ equivalent. This made the $\mathrm{EU}$ the third highest greenhouse emitter after the United States of America and China [1]. Despite the high emissions, the newest data indicate that the total amount of emitted greenhouse gasses has decreased for $23.2 \%$ below the 1990 levels [2]. The result has confirmed the EU's reach of the "20-20-20" energy saving target in terms of greenhouse emissions [3].

The decrease in energy use and greenhouse gas emissions is a consequence of several binding energy saving policies which are meant to serve as a mean for keeping and securing the descending trend of the energy use by the residential sector. In this regard, EU legal forces have introduced new, more challenging targets within "The 2030 climate and energy framework". According to this policy, the member countries of the EU need to locally apply strategies that will lead to at least: $40 \%$ cuts in the greenhouse gas emissions from the 1990 levels, $32 \%$ share of renewable energy and $32.5 \%$ improvement in energy efficiency [4]. Based on the existing 
measures, the latest projections foresee emission reductions of only about $30 \%$ by the 2030 [2] compared to the 1990 levels. Therefore, bigger investments, more binding measures and higher overall devotion in reaching better results in respect to the environmental climate conditions will become necessary.

Residential buildings are the biggest energy user in the EU after transport [5]. In the residential sector, the energy demand is a function of several factors such as weather and climate conditions, characteristics of the building structure, occupant behaviour. Space heating (SH) and domestic hot water requirements (DHW) have the highest share in total energy use among other typical energy consuming appliances of household facilities. In Belgium the residential buildings sector is responsible for about $23.23 \%$ of the total energy use. The energy demand is mainly covered by the supply of the natural gas with the share of about $41 \%$ of the total energy supply [6]. In order to reduce the energy use in buildings and thus aid the total aspirations towards lowering the emissions of greenhouse gasses, great interest is given to the reduction of the energy demands of the dwellings. Improvements in the building envelop as well as the use of more efficient heating, ventilation, air conditioning and refrigeration (HVAC\&R) equipment are currently being deployed.

The Energy performance of buildings directive (EPBD) imposes a requirement that all new residential buildings must be built as nearly zero energy buildings (NZEB) starting from the year 2020 [7]. An NZEB represents a building with low energy demand, which can mostly be covered from a renewable energy source exploited at the site or nearby [8]. Besides the construction of new NZEB buildings, many energy inefficient, old dwellings are currently being renovated with the intention to reduce their current energy demand. In the EU, there is a large potential for such action. For example, most of the Belgian households are built before the year 1990 [9] with the large share of insulated houses leading to an average space heating energy demand of 179 $\mathrm{kWh} / \mathrm{m}^{2}$ year [10]. With the conduction of renovation techniques that lead to NZEB standards, energy savings of residential buildings can be of up to $90 \%$, however, with the significant investment costs of up to $580 € / \mathrm{m}^{2}$ [11].

\subsection{Self-sufficiency of residential buildings}

At the present time, renewable energy supply systems (RES) such as photovoltaic panels (PV), heat pumps (HP) and solar thermal panels (STP) are finding an eminent place on the residential building market [12]. With their ability to generate the energy on site, a building becomes less dependent on the external grid supply thus leading to a certain potential of self-sufficiency reach. Moreover, the potential overproduction of electricity by the PV panels may be further supplied to the other residential or industrial users in their vicinity leading to increased sustainability of larger areas. Therefore, electricity demand can be partly covered by a PV system, while the heating demand can be covered by a HP, possibly in combination with a STP system. The level of autonomy or self-sufficiency is, however, limited due to the time mismatch between the on-site energy generation and energy demand.

Fig. 1 shows a schematic overview of a daily energy demand and energy generation profile of a grid-connected residential building provided by on-site renewable electricity production through PV panels.

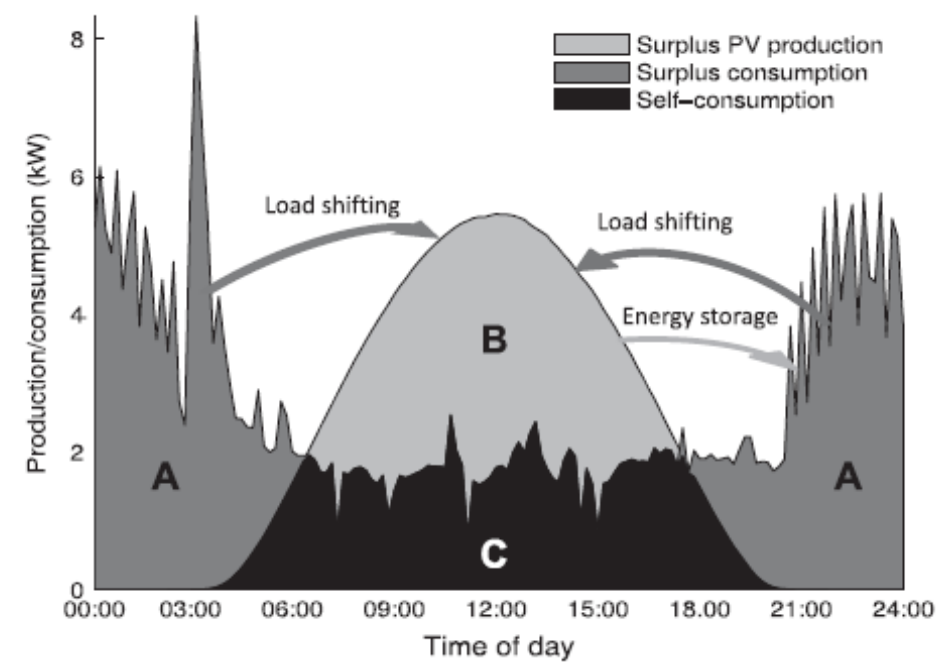

Fig. 1. A schematic overview of a daily energy use and generation profile of a residential building [13].

In Fig. 1 areas $A$ and $C$ represent the net energy need and thus the typical power demand trends often called U-shape demand or duck curve [14]. The energy demand C is directly covered from the renewable source while the area $B$ represents surplus energy production injected into the grid. Consequentially, the energy demand represented by the area $A$ is covered by the energy imported from the grid. 
From Fig. 1, two metrics that denote the interaction between the household and the grid can be defined: selfconsumption (SC) and self-sufficiency (SS). Self-consumption is defined as the ratio between the used instantaneous renewable energy produced on site to the total instantaneous renewable energy generation on site (area $C$ against the sum of the areas $B$ and $C$ ) while the self-sufficiency denotes the ratio of the used instantaneous renewable energy produced on site to the total instantaneous electrical energy demand of the building (area $\mathrm{C}$ against the sum of the areas $\mathrm{A}$ and $\mathrm{C}$ ).

In order to increase the values of SC and SS in the context of residential buildings, two main techniques are illustrated in Fig. 1 as well. At first, the load shifting technique refers to the movement of the time period with surplus energy consumption to periods with surplus energy production. In this way, the energy demand of a dwelling can be met for the optimal energy generation period for the best utilization of the available equipment and lower grid load. The second technique represents the energy storages implementation which are often charged at the times of surplus energy production or at lower billing tariffs and later utilized in the peak moment of energy demand. The increment of SC and SS values generally leads to the lowering of the grid overload and to the total increase of the efficiency of energy supply reflected in energy transport savings.

In this article, self-consumption and self-sufficiency of a low-energy demand residential building for impermanent operating conditions is analysed by means of using the thermal load shifting and the electrical energy storage strategies with transient detailed numerical simulations. The load shifting has been accomplished by the use of a thermal energy storage (TES) supplied by an air to water heat pump to meet the heating requirements of the dwelling while the electrical energy storage is realized with the use of a battery. In addition, the performance of the system has been compared to a possible replacement or combination of PV panels with STP system for generating thermal energy in order to analyse the impact in meeting the DHW demand and the overall energy demand of the dwelling. In this work, special attention is given on the equipment sizing, configuration and controlling strategy. The article concludes with a brief financial analysis on the subject.

\section{Case study description}

\subsection{Architectural properties of the building}

The architectural layout of the building is based on a real building that is a part of the social housing district Venning located in Kortrijk, Belgium [15]. The building is configured as a detached building with two floors and a gable type roof with the conditioned floor area of $99.8 \mathrm{~m}^{2}$. Fig. 2 shows the floor plans of the ground floor and the first floor.
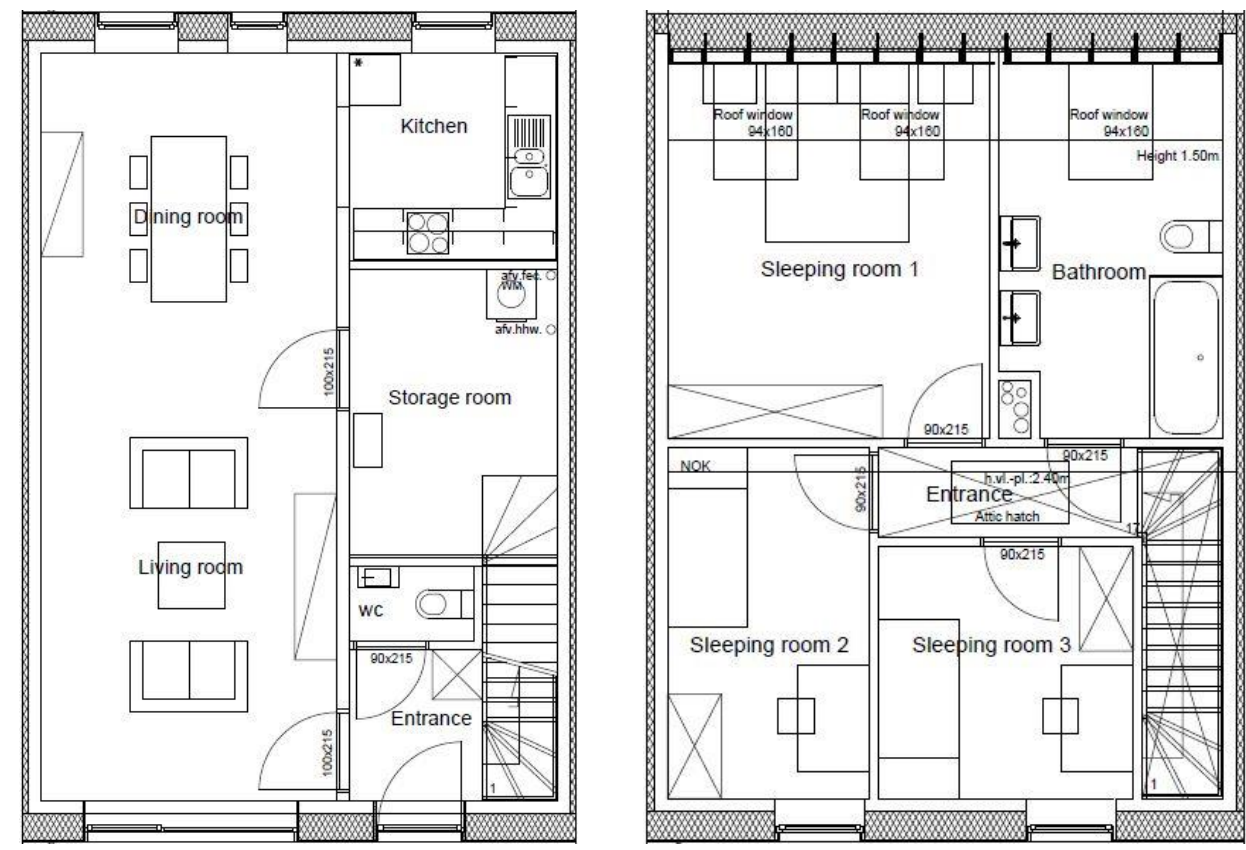

Fig. 2. Architectural layout of the modelled building structure. Ground floor (left), first floor (right).

The house is divided in 9 zones out of which 5 are heated. On the ground floor, the living room and kitchen are treated as a single zone thus further jointly referred as the living zone. Besides the living zone, three bedrooms and the bathroom zone located on the first floor are heated as well. The zones which do not require space heating are the entrance, the toilet room, storage room located on the ground floor and as well as the attic space, available through the hatch door on the first floor. The air tightness of the building is determined by the number of air changes per hour $(\mathrm{ACH})$ at the overpressure value of $50 \mathrm{~Pa}$. Therefore, for the airtightness 
of $1 \mathrm{ACH}$ and overall heat transfer coefficient of $0.282 \mathrm{~W} / \mathrm{m}^{2} \mathrm{~K}$, the building's annual heating demand is 2991 $\mathrm{kWh} / \mathrm{m}^{2} \mathrm{a}$ or $30 \mathrm{kWh} / \mathrm{m}^{2} \mathrm{a}$ in terms of specific heating demand.

\subsection{Boundary conditions}

During each of the simulations, the analysed building was subjected to the same boundary conditions. The yearly moderate climate data of the city Uccle in Belgium were used to simulate the weather conditions. The time step of the weather data is $1 \mathrm{~h}$ with the lowest reached temperature of $-7.61^{\circ} \mathrm{C}$.

A synthetic user profile is developed for each of the zones and it is based on the time survey data [16]. The profile corresponds to a young family with two adults and two children. The occupant behaviour includes coherent profiles for the set point temperatures of the zones, convective and radiative internal heat gains of the occupants and appliances, electricity demand of appliances and lighting, DHW demand and occupancy presence of the zones. The applied time-step is 10 minutes for the temperature set points and occupancy and 1 minute for the heat gains, electricity demand and DHW demand. The set point temperatures vary over the different zones. The living zone is heated to $20^{\circ} \mathrm{C}$ with a night setback to $15^{\circ} \mathrm{C}$ depending on the occupancy profile of the living zone. The indoor temperature in the rest of the rooms never falls below $15^{\circ} \mathrm{C}$.

On the household level, the internal heat gains of appliances and occupants result to be $4442 \mathrm{kWh}$ annually. With the average internal heat gain value of $403 \mathrm{~W}$, the living zone has the largest internal heat gains due to the presence of multiple appliances such as fridge, oven, television system etc. On the other hand, the annual electricity demand for lighting and appliances is $4351 \mathrm{kWh}$ for each household.

The DHW use was modelled to be dominant in this case study. With the constant supply of municipal water at $10^{\circ} \mathrm{C}$, and demand temperature set point of $40^{\circ} \mathrm{C}$, the annual DHW demand corresponds to $6732 \mathrm{kWh}$ of heating energy or $67.5 \mathrm{kWh} / \mathrm{m}^{2}$ a expressed via the conditioned floor area of the property.

\subsection{Building system installation description}

The ventilation system, heating system and electrical system installations are generally considered to take part of the building system installations. In this section, the applied composition and design choice of each of these systems will be described.

\subsubsection{Ventilation system}

Because of their high air tightness and indoor quality requirements, the NZEB houses are equipped with a ventilation system installation. However, despite not being in the focus of this work, a simple ventilation system is modelled and kept constant throughout the study. The system includes the fresh air supply to all of the zones of the dwelling and equal amount of air exhaust. Table 1 represents the modelled ventilation flow rates of the zones compared to the limiting values required by the Flemish EPB standard [17].

Table 1. Standardized and applied ventilation flow rates.

\begin{tabular}{lll}
\hline Zone & Limit values & Applied flow rates \\
\hline Living zone & $78-150 \mathrm{~m}^{3} / \mathrm{h}$ & $115.02 \mathrm{~m}^{3} / \mathrm{h}$ \\
Hall & & $33.48 \mathrm{~m}^{3} / \mathrm{h}$ \\
Storage & $50-75 \mathrm{~m}^{3} / \mathrm{h}$ & $50 \mathrm{~m}^{3 / \mathrm{h}}$ \\
Toilet & $25 \mathrm{~m}^{3 / \mathrm{h}}$ & $25 \mathrm{~m}^{3} / \mathrm{h}$ \\
Bedroom 1 & $28-72 \mathrm{~m}^{3} / \mathrm{h}$ & $54.58 \mathrm{~m}^{3} / \mathrm{h}$ \\
Bedroom 2 & $28-72 \mathrm{~m}^{3} / \mathrm{h}$ & $31.75 \mathrm{~m}^{3} / \mathrm{h}$ \\
Bedroom 3 & $28-72 \mathrm{~m}^{3} / \mathrm{h}$ & $28.94 \mathrm{~m}^{3} / \mathrm{h}$ \\
Bathroom & $50-75 \mathrm{~m}^{3} / \mathrm{h}$ & $50 \mathrm{~m}^{3} / \mathrm{h}$ \\
Attic & $25-72 \mathrm{~m}^{3} / \mathrm{h}$ & $25 \mathrm{~m}^{3} / \mathrm{h}$ \\
\hline
\end{tabular}

In order to prevent excessive waste of heat carried by the exhaust air, an air-to-air heat exchanger is modelled as part of the system. The heat exchanger is modelled as a heat recovery unit with constant efficiency of $84 \%$. The flows of the supply and exhaust air sides are not in physical contact nor mixed.

\subsubsection{Design and sizing of the space and daily hot water heating systems}

The applied heating system installation covers the space heating as well as the DHW energy demand in sequential order. Both of the systems are coupled to an air to water heat pump unit. The space heating system is enabled in the 5 heated zones through underfloor heating system installation in the serpentine shape. As an aspiration towards better efficiency of the heat pump unit, the chosen design temperature regime of the underfloor heating system is $35 / 25^{\circ} \mathrm{C}$. The total design space heating energy demand of the dwelling is 2813 $\mathrm{W}$. The chosen heat pump capacity is selected to meet the space heating demand while the same unit is also used to satisfy the DHW demand.

On the other hand, the DHW is provided through a fixed 300 I storage vessel. In the study, two DHW vessels have been considered. In the basic case, the vessel is heated by a single heating coil supplied from the heat pump. The DHW demand has the priority against the space heating demand. The heat pump, therefore, supplies the hot water either to the DHW vessel tank or to the space heating thermal energy storage (TES) 
which is further used to satisfy the space heating needs (to be elaborated further). In the second configuration of the DHW tank, a secondary heating coil has been integrated. The coil is located at the upper part of the tank and it is connected to the solar thermal panel system. The chosen working fluid of the STP system is propylene glycol-water mixture with $40 \%$ mass fraction of antifreeze additive. The solar collector is modelled according to the ASHRAE93 test standard [18]. A single collector has the area of $2 \mathrm{~m}^{2}$ and dry weight of $42 \mathrm{~kg}$. The model is based on the efficiency curve, which has a maximal efficiency of $77.5 \%$ and curve slope of -5.103 $\mathrm{W} / \mathrm{m}^{2} \mathrm{~K}$. In the active mode, an on/off circulation pump circulates the working fluid from the solar collector to the heating coil and thus aids the working performance of the heat pump.

Both of the DHW tank configurations have an additional electrical heater of $3 \mathrm{~kW}$ located at the top of each tank.

\subsubsection{Electrical system}

The electric system is modelled as a grid-connected PV battery system. The PV panel is modelled with the 5parameter model of De Soto et al., based on temperature dependent diode equivalent circuit $[19,20]$. The calculations are based on the manufacturer data for the nominal power of the PV panel of $230 \mathrm{Wp}$ with the surface of $1.4 \mathrm{~m}^{2}$. In this study, the amount of PV panels was varied between 10 to 50 . However, special attention was paid to the number of 20 PV panels which can cover about $90 \%$ of the Southside roof area of the building. Consequentially, all the PV panels are oriented directly southwards with an inclination angle of $34^{\circ}$. In the model, the power loss due to the conversion of the generated direct current to the alternating current is also accounted with the constant inverter efficiency of $95 \%$.

The electrical battery (EES) is modelled as a Li-on battery which has the charging efficiency of $87.4 \%$, discharging efficiency of $98 \%$ and a self-discharge of $3 \%$ per month. The operating range of the battery is $80 \%$ of its rated capacity.

\section{Modelling methodology}

\subsection{Controlling principle}

All the models and simulations are built in the programming language Modelica and software tool Dymola [21]. Most of the used models are parts of the two Modelica open-source libraries: IDEAS [22] and Buildings [23] library. The air to water heat pump model is a black box model developed within the IDEAS library. The model interpolates 8 performance tables that contain data related to the electrical power use and heat pump's heat capacity in the function of the outdoor temperature and set leaving water temperature. The performance data are made for full, $90 \%, 50 \%$ and $30 \%$ load rate of the unit. The model itself is dependent on the control of the feeding circulation pump. Therefore, if the mass flow rate given by the circulation pump is zero the heat pump shuts down. In addition, the model is controlled by the set leaving water temperature that switches between the control input of the heating curve mechanism or the set point temperature for feeding the coil of the DHW tank. Based on this temperature and information over the outdoor temperature, the right modulation stage is chosen with the consequential determination of the heat capacity and corresponding energy use for the set conditions. Besides the models available in the modelling libraries, a custom made auxiliary HP electrical heater and the water tank with two separated heating coils were used in this study.

In Fig. 3, a simplified hydraulic scheme of the heating system can be observed.

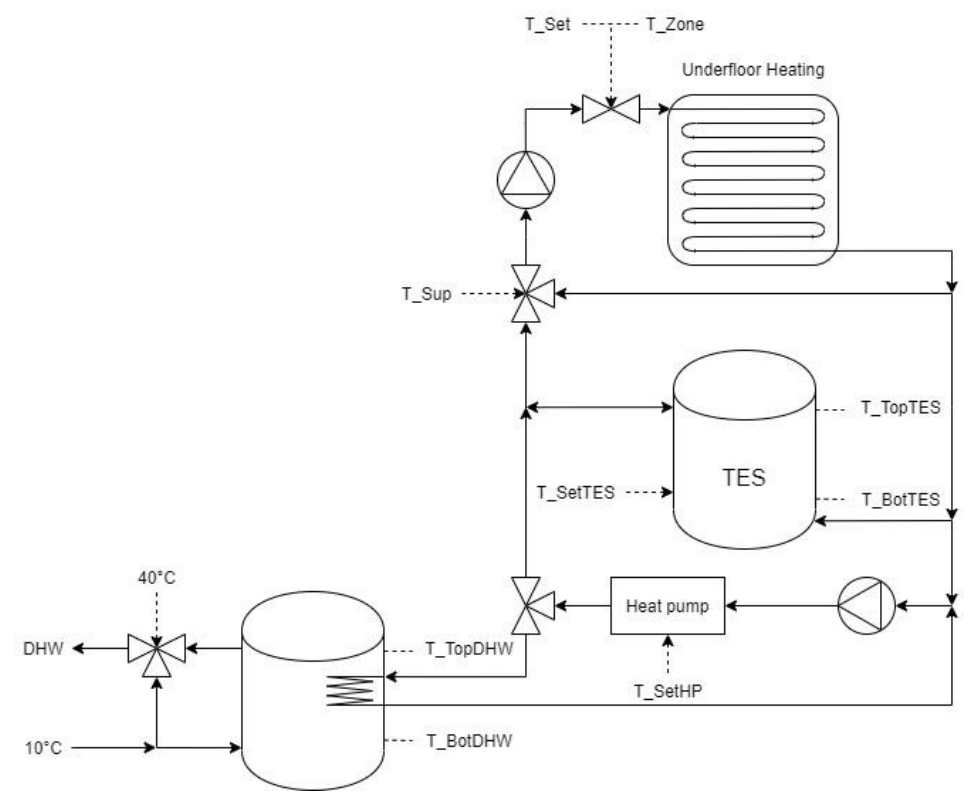

Fig. 3. A simplified hydraulic scheme of the basic heating system circuit. 
The switch between satisfying either DHW or SH demand causes mainly two actions. At first, the main three way valve located in front of the HP diverts the flow towards one of the circuits while the set point temperature of the HP switches from the value given either by the heating curve or by the DHW set point temperature of $50^{\circ} \mathrm{C}$. Since the DHW has priority over the SH demand, the performance switch occurs whenever the DHW bottom tank temperature TBotDHW drops below $40^{\circ} \mathrm{C}$ and switches back to $\mathrm{SH}$ when TBotDHW is above $46^{\circ} \mathrm{C}$. The electrical heater contained within the DHW water tank switches on when the top tank temperature TTopDHW drops below $40^{\circ} \mathrm{C}$ and switches off when TTopDHW is above $42^{\circ} \mathrm{C}$. Further, the DHW to the suppliers is provided with the temperature of $40^{\circ} \mathrm{C}$ achieved by the three way mixing valve utilizing the water from the DHW tank and freshwater.

On the SH side, the TES storage depicted in Fig. 3 is either used as a buffer vessel or as the TES storage if the load shifting strategy is considered in the simulation. In general, the HP is controlled based on the top (TTopTES) and bottom (TBotTES) tank temperatures and the tank set temperature (TSetTES). In the case when the buffer vessel is used, TSetTES is $2^{\circ} \mathrm{C}$ higher than the supply temperature for space heating (TSup), which is determined by the heating curve. The HP switches on when TTopTES drops below TSetTES and switches off when TBotTES has become higher than TSetTES. To be able to reach the switch-off condition, the HP condenser temperature TSetHP for space heating is set $5^{\circ} \mathrm{C}$ higher than TSetTES. The TES also contains a $3 \mathrm{~kW}$ electrical heating element that activates when TTopTES drops below TSup. The third three way valve is mixing the water from the top of the tank with water that is returned from the underfloor heating system to achieve the TSup provided to the underfloor heating system. The HP has an internal electrical heater of $3 \mathrm{~kW}$ that assists the HP on the coldest hours, only when the outside temperature is below $-5^{\circ} \mathrm{C}$.

The configuration of the hydraulic circuit involving the STP system is shown in Fig. 4. The STP system is used to aid in satisfying the dominant DHW demand of this case study and it is thus not having any direct influence on the TES and SH demand. The solar on/off circulation pump is used as the main controlling element for enabling the utilization of the STP system. The model is set to evaluate the difference between the current solar irradiance and the critical irradiance. The critical irradiance represents a factor calculated according to the Duffie and Beckman equation [24]. The factor is a function of the heat loss coefficient, ambient and inlet fluid temperatures as well as of the maximal efficiency. The solar circulation pump immediately turns off if the inlet temperature of the fluid reaches $100^{\circ} \mathrm{C}$.

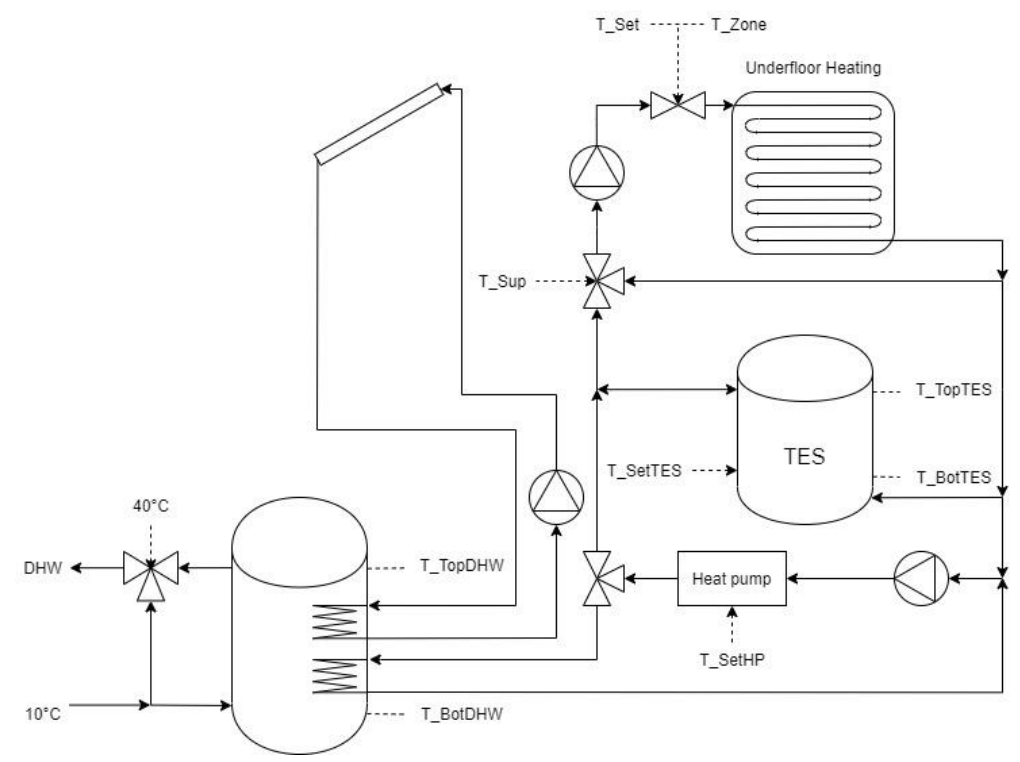

Fig. 4. A simplified hydraulic scheme of the heating system circuit including the solar collector system.

On the side of the electrical installations, the EES is charged when there is an extensive PV generation of electricity. Last only occurs when the instantaneous renewable energy production is larger then the instantaneous sum of the electrical loads of the HP, electrical heaters, appliances and lighting. The charging of the battery takes place until the battery is fully charged. When the buffer tank is used as TES, as part of the load shifting strategy, the TES is charged by the HP which then changes its water set point temperature to $55^{\circ} \mathrm{C}$ thus overheating the TES. The TES is charged when there is a persistent overproduction of PV for longer than 10 minutes and the battery is fully charged. In this way, the electrical energy storage is prioritized over the TES. If the electricity demand on the household level is satisfied, the overproduction of electricity is injected into the grid. The grid is not explicitly modelled in this study and it is therefore considered as an ideal voltage source. 


\section{Results}

\subsection{Increasing self-sufficiency and self-consumption with PV panels and energy storages}

All system modelling configurations are simulated at the same weather conditions, occupancy behaviour, energy use of the appliances and SH and DHW demand. In the study, the comparison in the potential reach of SS and SC was referenced to the basic case. In the basic case, the electrical power is generated at the site out of $20 \mathrm{PV}$ panels with the total area of $28 \mathrm{~m}^{2}$, which covers about $90 \%$ of the Southside roof space of the building. The overproduction of electrical energy is injected into the grid and hence, the basic case considers the installation without the use of TES and EES. Further, the total generated amount of electrical energy is $4303 \mathrm{kWh}$ with the total electricity demand of $7769 \mathrm{kWh}$ out of which $5657 \mathrm{kWh}$ are imported from the grid. Hence, with the absolute self-consumption of $2112 \mathrm{kWh}$ (immediately covered by the PV energy generation), the buildings basic configuration results in SC and SS of $49.1 \%$ and $27.2 \%$ respectively.

Fig. 5 and Fig. 6 give the results of SC and SS for the variations of the amount of used PV panels and sizes of the TES and EES. In total, 125 simulations were executed for a year duration in order to obtain the results. In the simulations, the number of PV panels was changed between 10, 20, 30, 40 and 50 PV panels while the TES size was varied between 0 I to 2000 I and the EES capacity between $0 \mathrm{kWh}$ to $20 \mathrm{kWh}$. In Fig. 6 the maximal value of the SS for the amount of simulated PV panels is shown as well. The maximal SS value is achieved if the annual PV generation is equal to the annual electricity demand which can be attained if the SC results in $100 \%$ (entire PV generation is self-consumed).

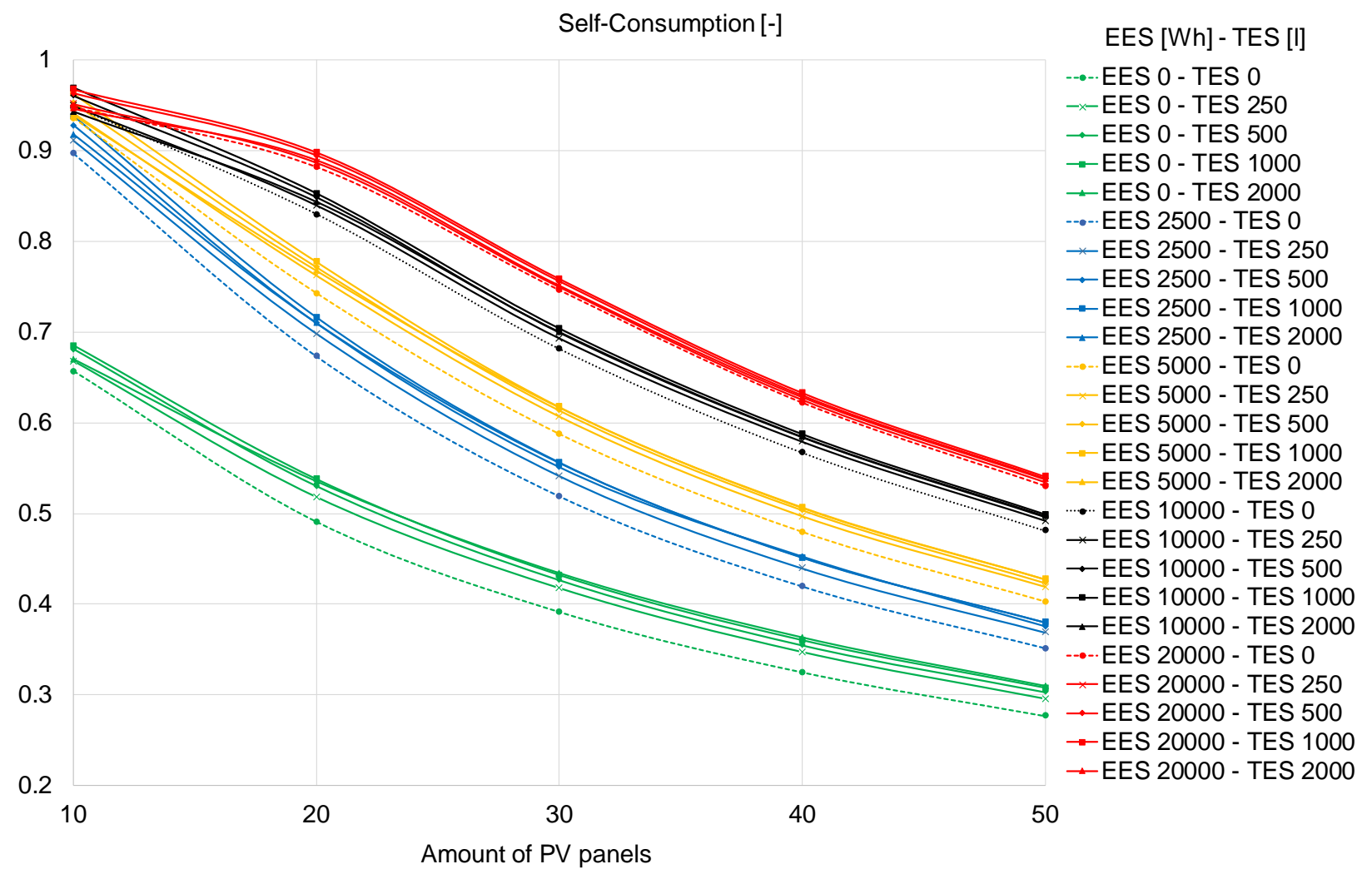

Fig. 5. Self-Consumption results for different PV, EES and TES sizes.

In both figures, the results indicated with the same colour correspond to the same EES simulated capacity while the dotted lines represent the reference, base case without TES. As the PV system has more PV panels, the SC value becomes lower while the SS value becomes higher. Moreover, due to the higher electricity generation out of the PV panels it becomes more difficult to achieve $100 \%$ SC and the maximum SS. This is not surprising, as the PV generation is proportional to the amount of PV panels and SC is equal to the absolute self-consumption relative to the PV generation.

The impact of EES is much larger than the thermal load shifting in the analysed case study. The smallest EES of $2.5 \mathrm{kWh}$ increases SC and SS to $67.3 \%$ and $37.3 \%$ respectively. Each doubling of the EES capacity increases SC and SS values further. With the largest EES of $20 \mathrm{kWh}$ and without thermal load shifting, SC of $88.2 \%$ and SS of $48.9 \%$ can be achieved. With $20 \mathrm{PV}$ panels and without EES, performing thermal load shifting with the TES of 250 I increases SC and SS to respectively to $51.8 \%$ and $28.7 \%$, which is an increase of 
respectively $2.7 \%$ and $1.5 \%$ compared to the base case without thermal load shifting. Still without EES, further increment of the TES size to 1000 I can increase SC and SS values to $53.8 \%$ and $29.8 \%$ respectively. Doubling the TES size once again can not increase SC and SS beyond these values. When combining EES and thermal load shifting, the pattern of SC and SS as a function of TES size does not change significantly. The highest SC and SS values that are achieved with 20 PV panels in this case study are respectively $89.8 \%$ and $49.8 \%$ and require a battery with $20 \mathrm{kWh}$ rated capacity and a TES of $1000 \mathrm{I}$.

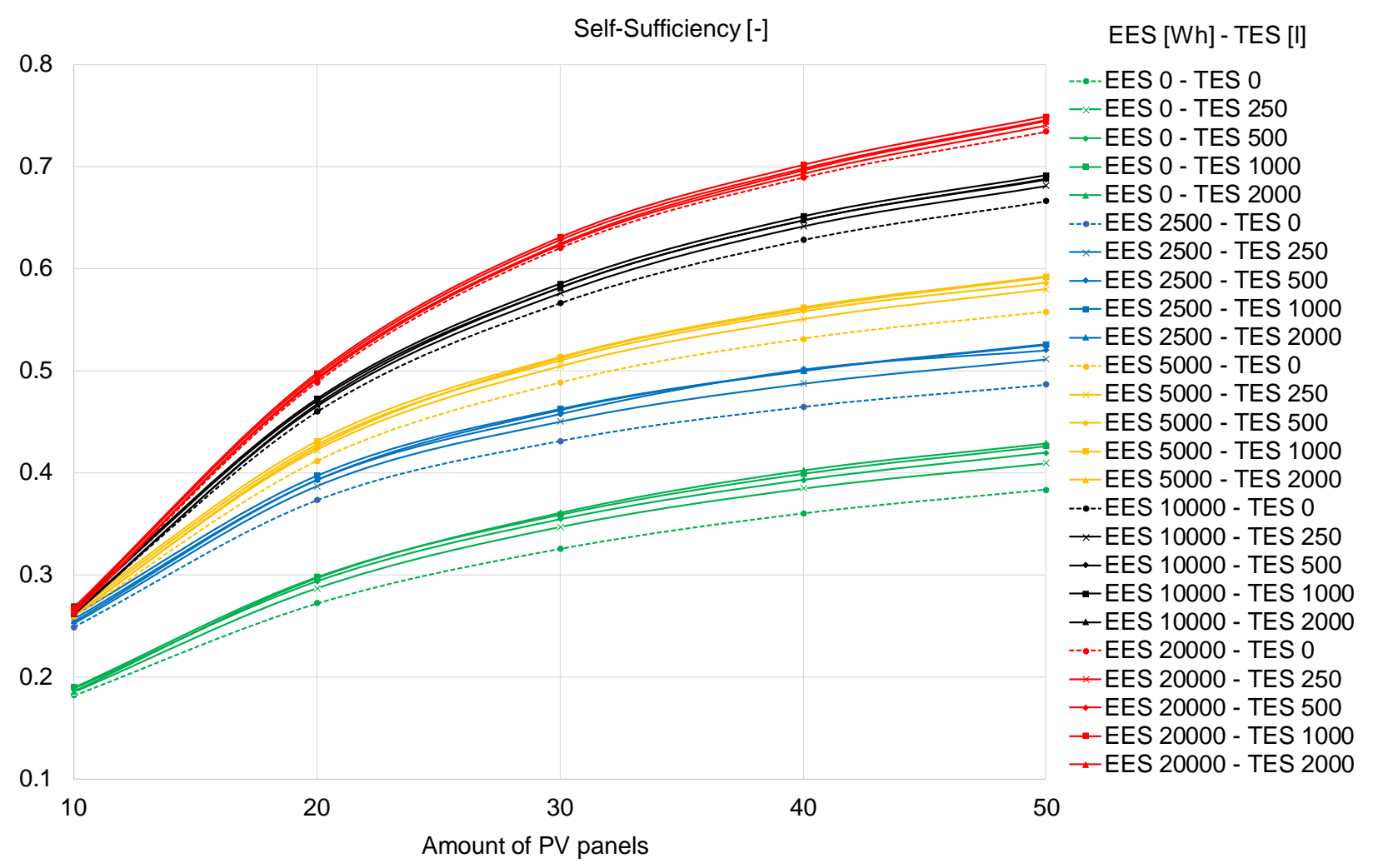

Fig. 6. Self-Sufficiency results for different PV, EES and TES sizes.

Another way to interpret the results is by determining the minimum system requirements in order to achieve a certain degree of SS. Achieving the same value of SS is possible in multiple ways. For example, SS of approximately $50 \%$ can be achieved in the following 4 ways:

- $28 \mathrm{~m}^{2} \mathrm{PV}, 20 \mathrm{kWh}$ EES and 1000 I TES.

- $42 \mathrm{~m}^{2} \mathrm{PV}, 5 \mathrm{kWh}$ EES and 250 I TES.

- $56 \mathrm{~m}^{2} \mathrm{PV}, 2.5 \mathrm{kWh}$ EES and 1000 I TES.

- $70 \mathrm{~m}^{2}$ PV, $2.5 \mathrm{kWh}$ EES and 250 I TES.

These four systems correspond with SC values of $89.8 \%, 60.7 \%, 45.1 \%$ and $36.9 \%$ respectively. The choice of the installed system depends on the multiple factors such as the available space for placing the PV panels, investment costs, billing method etc.

\subsection{Increasing self-sufficiency and self-consumption with STP and PV panels and energy storages}

In order to satisfy the dominant DHW of this case study, an analysis was conducted on integrating the solar thermal collector panels (STP) as part of the heating system. In the analysis, the available Southside roof space area of the building was used for either placing only the STP system or in the combination with the PV panels system. The goal of the study was to reduce the electrical energy demand of the heat pump system which was the only energy source for meeting the DHW demand in the previous system configuration. Naturally, with the reduction of the number of PV panels the generation of the electrical power will decrease, however, the placement of the STP still has a potential to increase the overall SS value of the dwelling.

In this part of the study, 100 simulations were executed and processed. The number of STP and PV panels was set in four different ratios for the available Southside roof are of $28 \mathrm{~m}^{2}$ :

- STP $=0 \mathrm{~m}^{2}, \mathrm{PV}=28 \mathrm{~m}^{2}$.

- $S T P=7 \mathrm{~m}^{2}, P V=21 \mathrm{~m}^{2}$.

- $S T P=14 \mathrm{~m}^{2}, P V=14 \mathrm{~m}^{2}$.

- $S T P=21 \mathrm{~m}^{2}, P V=7 \mathrm{~m}^{2}$. 
In order to make the best use out of a larger set of STP system, the DHW tank size has to be larger as well and it was therefore chosen to be $300 \mathrm{I}, 450 \mathrm{I}$ and $600 \mathrm{I}$ for the STP surfaces of $7 \mathrm{~m}^{2}, 14 \mathrm{~m}^{2}$ and $21 \mathrm{~m}^{2}$ respectively. As in the previous case, the TES size was varied between $0 \mathrm{I}$ to $2000 \mathrm{I}$ and the EES capacity between $0 \mathrm{kWh}$ to $20 \mathrm{kWh}$. Fig. 7 and Fig. 8 show the results on the self-consumption and self-sufficiency values for the made simulations. The results indicated with the same colour correspond to the same EES simulated capacity while the dotted lines represent the reference, base case without TES.

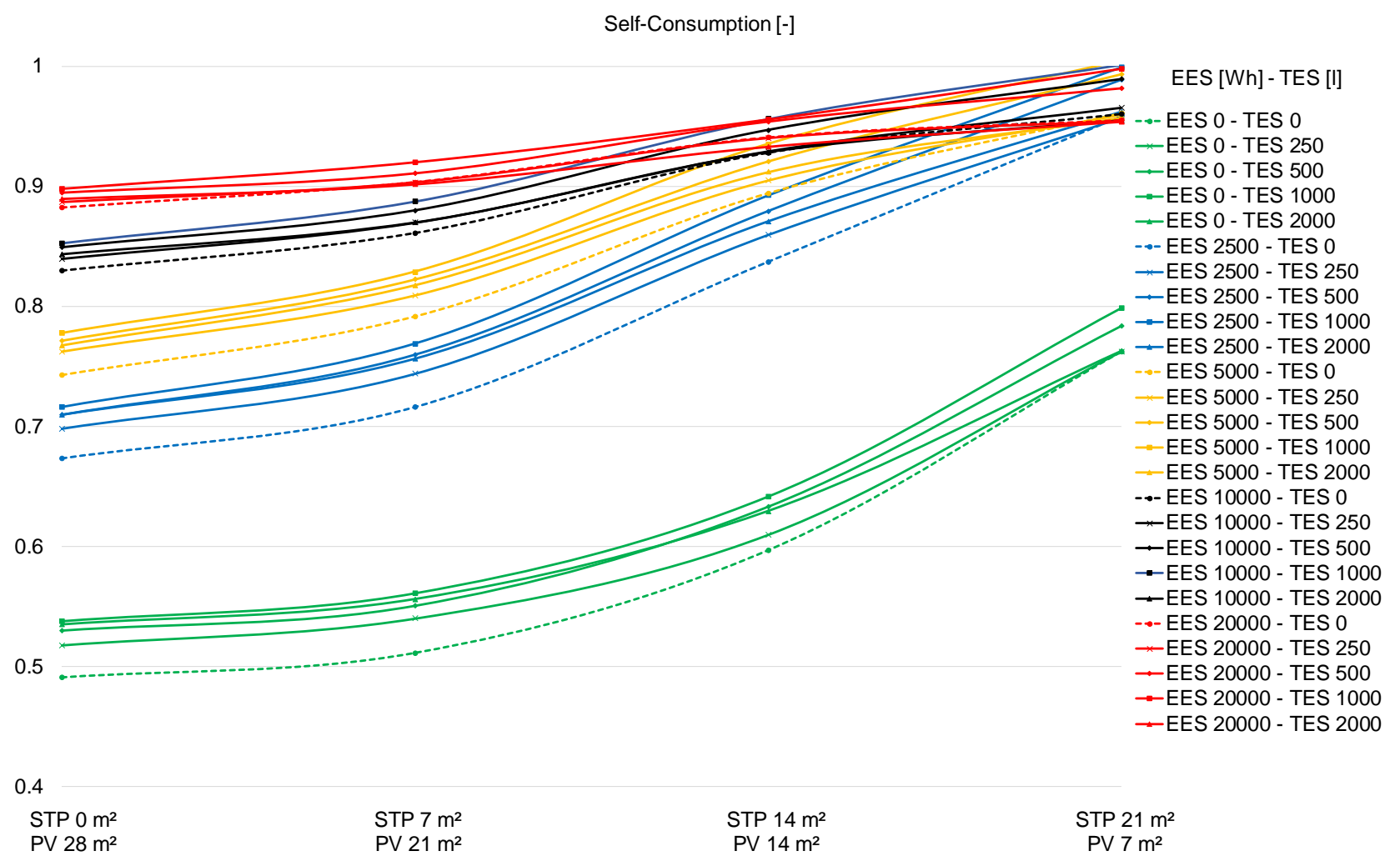

Fig. 7. Self-Consumption results for different STP, PV, EES and TES sizes.

Despite replacing PV panels with STP system increases SC and reduces the electricity demand of the dwelling, SS values are significantly reduced for the studied cases. $7 \mathrm{~m}^{2}$ of solar collectors reduces the electricity demand for $443 \mathrm{kWh}$ while the reduction of $7 \mathrm{~m}^{2} \mathrm{PV}$ panels reduces the electricity generation for $1076 \mathrm{kWh}$. For the considered case, the maximum SS that can be obtained thus reduces when replacing PV panels by ST panels. This does not necessarily mean that the actual SS values are lower, because the higher the PV generation, the harder it becomes to achieve SC of $100 \%$ or the maximum SS. Hence, this analysis suggests that if the heating system includes a HP, PV panels are more effective for raising the SS of the dwelling despite that the STP system decreases the overall energy demand of the dwelling. The reason is that the generation of useful energy of PV and STP systems coincide in time and that a certain area of STP can not reduce the electricity demand sufficiently to compensate for the loss in PV generation for the same reduced area of PV. Therefore, for the properties of this case study, it is not advised to install STP system on the cost of reducing the number of installed PV panels. 


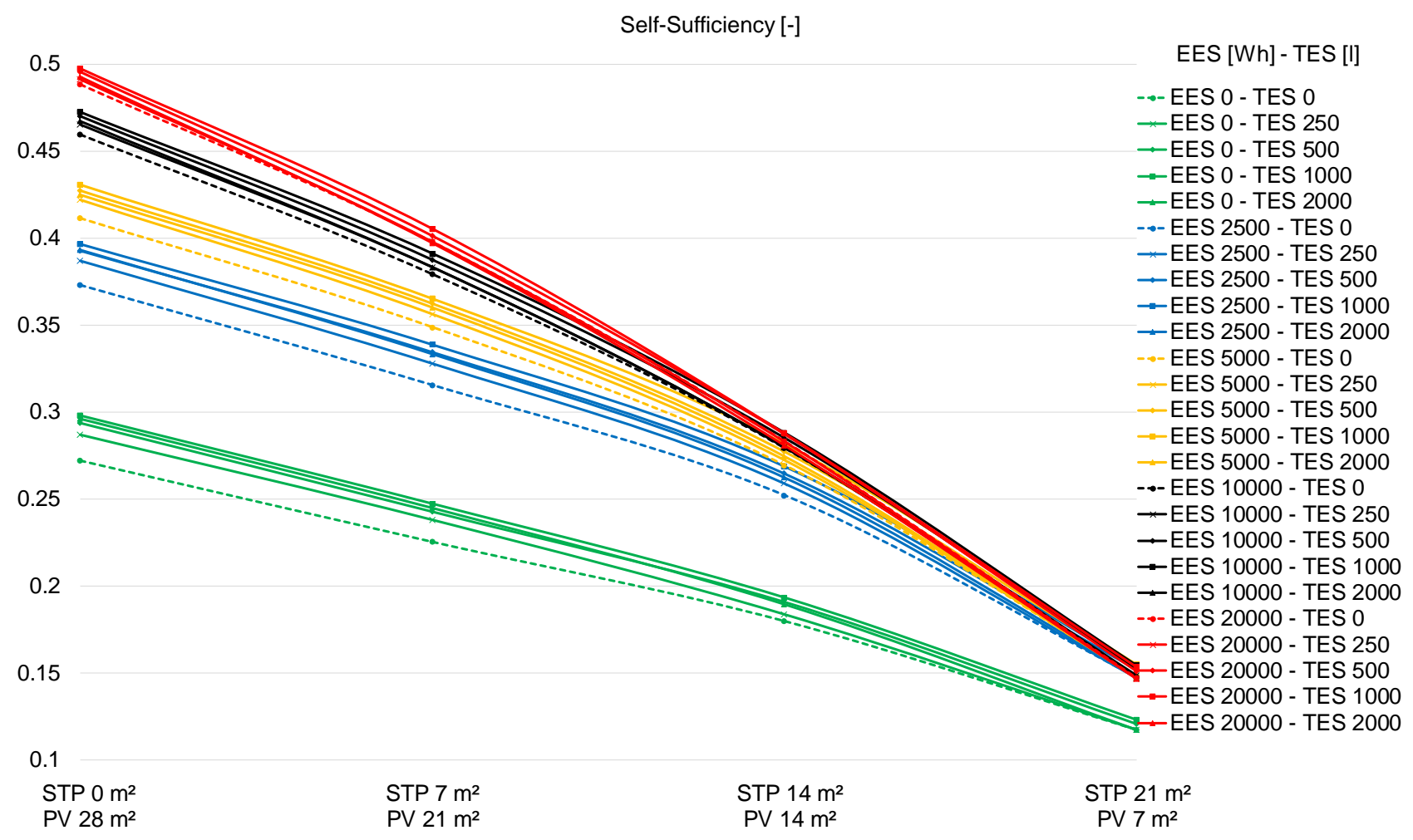

Fig. 8. Self-Sufficiency results for different STP, PV, EES and TES sizes.

\section{Financial perspectives}

Most of the investments in the technical household systems are motivated and often conditioned by the current economical statistics and future predictions. As mentioned earlier, there are myriad of factors which should be taken into account from the economical perspective such as the retail price of electricity, investment costs of the equipment, maintenance costs, life cycle of the equipment etc. For the Belgium market, two different billing tariffs are worth to be analysed. The first billing tariff refers to the current, phasing out charges according to which, for the systems that include the generation of electricity by PV panels, the net annual electricity price calculates according to Equation (1):

$$
\text { Annual bill }=\left(E_{i m p}-E_{i n j}\right) \cdot C_{e l}+C_{\text {prosumer }}
$$

where $E_{i m p}$ represents the electrical energy imported from the grid, $E_{i n j}$ energy injected into the grid while $C_{e l}$ and $C_{\text {prosumer }}$ are the average retail unit electricity price and prosumer tariff respectively. On the Belgium market, a PV installation with inverter costs and corresponding taxes currently has an approximate cost of $€ 1484$ per $\mathrm{kWp}$. With the average retail price of the electricity price of $€ 0.286 \mathrm{kWh}$ and prosumer tariff of $€ 105.94$ per installed kWp of the inverter for the city Kortrijk in Belgium [25], Table 2 provides the overview of the investment and payback time for different PV sizes and net electricity cost:

Table 2. The overview of the investment costs and payback time for different PV sizes and current billing calculations

\begin{tabular}{llllll}
\hline $\mathrm{PV}$ & Investment & $E_{\text {imp }}-E_{\text {inj }}$ & Annual bill & Annual savings & Payback time \\
\hline $0 \mathrm{~m}^{2}$ & $€ 0$ & $7769.2 \mathrm{kWh}$ & $€ 2222.0$ & $€ 0$ & 0 years \\
$14 \mathrm{~m}^{2}$ & $€ 3413.2$ & $5607.5 \mathrm{kWh}$ & $€ 1847.4$ & $€ 374.6$ & 9.11 years \\
$28 \mathrm{~m}^{2}$ & $€ 6826.4$ & $3465.8 \mathrm{kWh}$ & $€ 1478.6$ & $€ 743.5$ & 9.18 years \\
$42 \mathrm{~m}^{2}$ & $€ 10239.6$ & $1312.2 \mathrm{kWh}$ & $€ 1106.3$ & $€ 1115.7$ & 9.18 years \\
\hline
\end{tabular}

The current billing method does not compensate for the energy injected back into the grid. For this reason, it is not economically beneficial for a household to generate more energy than used. However, despite the additional prosumer tariff, a larger PV size results in higher annual savings. In respect to the application of an EES or TES strategy, with the current billing method, the effort implies not to be economically favourable as both strategies for increasing SS and SC are reducing $E_{i m p}$ and $E_{i n j}$ with approximately the same rate.

At present time, in Belgium, the current electricity meters are being replaced by so called smart meters, which are able to precisely register the amount of electrical energy imported and exported from the grid. In addition, the prosumers tariff is not fixed but based on grid energy import without exploitation costs. The charging system 
is based on the electrical energy taken from the grid that is reduced by the amount of electrical energy injected back into the grid. The overview of the billing calculation is given in Equation (2):

$$
\text { Annual bill }=E_{\text {imp }} \cdot C_{\text {el }}-E_{\text {inj }} \cdot C_{\text {el,imp }}
$$

In Belgium, the price of the imported and exported electrical energy may be negotiated with the energy provider. For the analysed case, the price of the imported electricity $C_{e l, i m p}$ is considered to be $€ 0.06 \mathrm{kWh}$. Table 3 shows the overview of the annual savings and payback time of the investment for the new billing method and the same PV system installation as in the previous analysis. The results indicate shorter payback time in the case of the system with $10 \mathrm{PV}$ panels $\left(14 \mathrm{~m}^{2}\right)$ and longer payback time in the case of using 20 (28 $\left.\mathrm{m}^{2}\right)$ and $30\left(42 \mathrm{~m}^{2}\right) \mathrm{PV}$ panels. The annual savings result to be higher in the case of the 10 and $20 \mathrm{PV}$ panels and lower in the case of the $30 \mathrm{PV}$ panels. Further, the new billing tariff method intrigues interest in analysing the investments in installations that increase self-consumption and self-sufficiency of the property.

Table 3. The overview of the investment costs and payback time for different PV sizes and future billing calculations

\begin{tabular}{lllllll}
\hline PV & Investment & $E_{\text {imp }}$ & $E_{\text {inj }}$ & Annual bill & $\begin{array}{l}\text { Annual } \\
\text { savings }\end{array}$ & $\begin{array}{l}\text { Payback } \\
\text { time }\end{array}$ \\
\hline $0 \mathrm{~m}^{2}$ & $€ 0$ & $7769.2 \mathrm{kWh}$ & $0 \mathrm{kWh}$ & $€ 2222.0$ & $€ 0$ & 0 years \\
$14 \mathrm{~m}^{2}$ & $€ 3413.2$ & $6356.0 \mathrm{kWh}$ & $748.5 \mathrm{kWh}$ & $€ 1772.9$ & $€ 449.1$ & 7.6 years \\
$28 \mathrm{~m}^{2}$ & $€ 6826.4$ & $5657.2 \mathrm{kWh}$ & $2191.4 \mathrm{kWh}$ & $€ 1486.5$ & $€ 735.5$ & 9.28 years \\
$42 \mathrm{~m}^{2}$ & $€ 10239.6$ & $5242.6 \mathrm{kWh}$ & $3930.3 \mathrm{kWh}$ & $€ 1263.5$ & $€ 958.5$ & 10.68 years \\
\hline
\end{tabular}

Simply, the analysed PV size cases can be compared for the use of EES and TES by calculating the total cost that represents the sum of the investment costs and variable costs based on the electricity price, equipment lifetime and discount factor of $4 \%$ per year [26]. Without PV panels, the net present cost of the electricity bill for the next 20 years is $€ 301797.7$. Considering the investment of $€ 500$ for every 1000 I TES storage and $€ 600$ for every extra kWh of the EES rated capacity, 20 PV panels, $2.5 \mathrm{kWh}$ EES capacity and a 1000 I TES storage equipment combination results in SC of $71.6 \%$, SS of $39.7 \%$ and in approximately $€ 3990$ saving over the time span of 20 years. For the analysed case study, the most economical solution includes the system with 20 PV panels and an EES of $2.5 \mathrm{kWh}$ with about $€ 4085$ of savings in the period of 20 years.

\section{Conclusion}

Residential buildings are responsible for a significant share of the total energy use in the European Union. The current and new energy saving policies are implying higher investments in this sector in terms of improving the building structure and decreasing the total energy demand with the application of energy efficient equipment supplied by renewable energy sources generated on site.

In this work, the potential increment of self-sufficiency (SS) and self-consumption (SC) was numerically evaluated for a low energy demand building, which has a dominant daily hot water demand (DHW) over the space heating need. In order to inspect the impact of thermal load shifting (TES) and electrical energy storage (EES) on the used case building, the amount of PV panels, thermal energy storage size and capacity of electrical energy storage was varied in the numerical simulations. For the use of $28 \mathrm{~m}^{2}$ of photovoltaic panels, the studied building achieves $49.1 \%$ of self-consumption and $27.2 \%$ self-sufficiency without any use of energy storages. With an electrical battery of $20 \mathrm{kWh}$ and thermal energy storage of $1000 \mathrm{I}$, the building can meet self-consumption of $89.8 \%$ and self-sufficiency of $49.8 \%$ for the specific boundary conditions. The impact of introducing an EES system in the installation is much larger than the one of the TES.

In addition to the main simulations, an analysis was made on the impact of replacing and combining the PV panels system with the solar thermal collector system (STP) for the same EES and TES size variations. Despite replacing PV panels with STP system increases SC and reduces the electricity demand of the dwelling, SS values are significantly reduced for the studied cases.

The results of the basic financial analysis for the future planned billing tariffs of electrical energy in Belgium suggest the implementation of the system which considers 20 PV panels and a $2.5 \mathrm{kWh}$ EES capacity that leads to approximately $€ 4085$ saving over the time period of 20 years. With the aspirations towards lower costs of the PV panels and battery storages and governmental subsidies, further research in this field is strongly advised.

\section{References}

[1] News European Parliament. Greenhouse gas emissions by country and sector - Available at: $<$ https://www.europarl.europa.eu/news/en/headlines/priorities/climatechange/20180301ST098928/greenhouse-gas-emissions-by-country-and-sector-infographic> [accessed: 06.02.2021].

[2] EEA. Trends and projections in Europe 2019, tracking progress towards Europe's climate and energy targets ISSN; 2019. Technical Report No.: 15/2019. 
[3] European Commission. 2020 climate \& energy package. - Available at: $<$ https://ec.europa.eu/clima/policies/strategies/2020 en\#tab-0-0> [accessed: 06.02.2021].

[4] European Commission, "2030 climate \& energy framework. - Available at: $<$ https://ec.europa.eu/clima/policies/strategies/2030 en> [accessed: 24.1.2020].

[5] Tzeiranaki A. T., Bertoldi P.,Diluiso F.,Castellazzi L.,Economidou M.,Labanca N., Serrenho T. R., Zangheri P., Analysis of the EU residential energy consumption: Trends and determinants. Energies 2019;12.

[6] Odyssee-Mure and Horizon 2020. Belgium, Energy profile February 2021, Energy efficiency trends and policies; 2021 Feb. Technical report.

[7] European Commission. Energy performance of buildings directive - Available at: $<$ https://ec.europa.eu/energy/en/topics/energy-efficiency/energy-performance-of-buildings/energyperformance-buildings-directive $>$ [accessed: 06.02.2021].

[8] Becchio C., Corgnati S. P., Vio M., Crespi G., Prendin L., Ranieri M., Vidotto D., Toward NZEB by optimizing HVAC system configuration in different climates. Energy Procedia 2017;140:115-126.

[9] Jespers K., Dams Y., Kristien A., Pascal S., Frederic J., and Laurent D., Energy Consumption Survey for Belgian households; 2012. Technical report.

[10] Bertelsen N., Mathiesen B. V., EU-28 residential heat supply and consumption: Historical development and status. Energies 2020;13.

[11] BPIE. Europe's buildings under the microscope, A country-by-country review of the energy performance of buildings; 2011. Technical report.

[12] Monteyne H., Simic K., Lazova M., Laverge J., Paepe D. M., Autonomy of low energy residential houses in Belgium using photovoltaic panels and energy storage. Proceedings of the 25th IIR International Congress of Refrigeration; 2019 August 24-30; Montreal, Canada:5030-5038.

[13] Luthander R., Widén J., Nilsson D., Palm J., Photovoltaic self-consumption in buildings: A review. Applied Energy 2015;142:80-94.

[14] Leonard M.D., Michaelides E. E., Grid-independent residential buildings with renewable energy sources. Energy 2018;148:448-460.

[15] Eco-Life. Sustainable zero carbon ECO-town developments improving quality of life accross EU Available at: <http://www.ecolife-project.eu/> [accessed: 06.02.2021].

[16] Baetens R., Saelens D., Modelling uncertainty in district energy simulations by stochastic residential occupant behavior. Journal of Building Performance Simulations 2015; 9:4:431-447.

[17] VEA. Bijlage V-Bepalingsmethode EPW - Bepalingsmethode van het peil van primair energieverbruik van residentiële eenheden; 2017 Dec. Technical report.

[18] ASHRAE. Method of testing to determine the thermal performance of solar collectors. (ASHRAE standard). Atlanta, USA; 1985. Technical report.

[19] De Soto W., Klein S. A., Beckman W. A., Improvement and validation of a model for photovoltaic array performance. Solar Energy 2005;80:78-88.

[20] Sera D., Teodorescu R., Rodriguez P., PV panel model based on datasheet values. Proceedings of the IEEE International Symposium on Industrial Electronics; 2017 Jun 4-7; Vigo, Spain:2392-2396.

[21] Modelica Association. Modelica $\AA$ - A Unified Object-Oriented Language for Systems Modeling, Language Specification; 2017.

[22] Aertgeerts A., Baetens R., Coninck R.D., Jorissen F., Picard D., Reynders G., Roy J., Verbruggen B., IDEAS v2.1. - Modelica, open-source library; 2019. Leuven, Belgium.

[23] University of California, Lawrence Berkeley National Laboratory. Buildings Modelica library 6.0.0.

[24] Duffie J. A., Beckman W. A., Solar Engineering of Thermal Processes. 4th ed. Wiley; 2013.

[25] Vlaamse Regulator van de Elektriciteits- en Gasmarkt. Prosumententarief 2020 - Available at: $<$ https://www.vreg.be/nl/prosumententarief-2020 > [accessed: 06.02.2021].

[26] Bellos E., Tzivanidis C., Moschos K., Antonopoulos K. A., Energetic and financial evaluation of solar assisted heat pump space heating systems. Energy conversion management 2016;120:306-319. 